\title{
Recent advanced techniques in cysteine determination: a review
}

\author{
${ }^{1}$ Mohamad Zharif, Z., ${ }^{1, * N u r}$ Azira, T., ${ }^{1}$ Muhamad Shirwan, A.S. and ${ }^{2}$ Azilawati, M.I. \\ ${ }^{1}$ International Institute for Halal Research and Training (INHART), Level 3, KICT Building, International \\ Islamic University Malaysia (IIUM), 53100 Jalan Gombak, Selangor, Malaysia \\ ${ }^{2}$ JAKIM Malaysia Halal Analysis Centre (MyHAC), Halal Hub Division, Department of Islamic \\ Development, No. 1, Persiaran Teknologi 1, Lebuh Enstek, 71760 Bandar Baru Enstek, Negeri Sembilan, \\ Malaysia
}

\author{
Article history: \\ Received: 23 April 2020 \\ Received in revised form: 31 \\ May 2020 \\ Accepted: 8 June 2020 \\ Available Online: 3 August \\ 2020 \\ Keywords: \\ Cysteine, \\ E920, \\ Food additives, \\ Food security, \\ Analytical method
}

DOI:

https://doi.org/10.26656/fr.2017.4(6).189

\begin{abstract}
The utilization of cysteine in a wide variety of products especially bakery products has led to a huge concern of various groups of consumers especially those who restricted to religious-based dietary. It has become a major concern due to the raw materials are derived from arguable sources such as pig bristles and human hair. This review briefly elaborates cysteine as food additives with highlighted issues in halal perspective and toxicity in the food industry. This review also highlighted several analytical approaches used in direct determination of cysteine compound such as high performance liquid chromatography (HPLC), molecular imprinted polymers (MIPs), Raman spectroscopy, flow injection spectrophotometric, electrochemical biosensor and gold nanoparticles based calorimetric assay
\end{abstract}

\section{Introduction}

Cysteine is an amino acid common to many proteins and enzyme. It is of interest due to the presence of a reactive thiol group as a side chain (Hunt, 1985; Gmunder et al., 1990; Demirkol et al., 2004). As a control functionalization of thiols, cysteine has it important roles in detoxification of heavy metals in living organisms, antioxidant capabilities of tissues and mitochondria, blood coagulation in mammals, transport across cell membranes and electrochemical sensing (Sirko et al., 2004; Wirtz et al., 2004; Wirtz and Droux, 2005; Borase et al., 2015; Cebi et al., 2017). Cysteine usually found in relatively low concentration in dietary protein which does not exceed $5 \%$ of total amino acids (Demirkol et al., 2004; Ismail et al., 2014). They can be found in whole foods such as meat, grains, nuts, fruits and vegetables. Production of cysteine in the worldwide market can reach up to 400 tons (Berehiou et al., 2013) where the major production was used as food additives (Ismail et al., 2014). It acts as a stabilizer in bakery ingredients by softening the texture of the yeast and preventing from further oxidation (Wada and Takagi, 2006; Wu, 2013; Ismail et al., 2014) while in animal food production it is been used as artificial flavour by mimicking meat flavour (Cao et al., 2017).

Nonetheless, cysteine production raised an ethical issue and consumer concern upon the source of the raw materials. The availability of cysteine food additives in the food industry is majorly derived from keratin hydrolysis (Ryu et al., 1997; Berehoiu et al., 2013; Ismail et al., 2014). Precisely, the keratin sources are extraction product from human hair or animal parts such as feathers, bristles or hooves (Frape et al., 1971; Cebi et al., 2017). Cysteine extraction from human hair is widely used due to its abundantly available and low-cost production. Apart from that, cysteine production might come from the fermentation process. The process involved enzymatic bioconversion from two type bacteria strains which Pseudomonas sp. and E. coli (Sano and Mitsugi, 1978; Tamura et al., 1998). The enzymatic bioconversion method has been used by Ajinomoto Co. Inc., Japan in industrial scale (Wada and Takagi, 2006; Ismail et al., 2014). The doubtful sources of cysteine may be criticized in different aspects especially in religion practice consumers. The goal of this review is to cover recent advances in cysteine determination techniques. This review also discusses the physical and chemical structure of cysteine, its 
applications specifically in the food industry, and food safety issues of cysteine as additives.

\section{Cysteine amino acids and its religious issue}

Amino acids (AA) are important for growth and development. It acts as precursors for building up proteins and other biologically important substances such as peptides, hormones and enzyme (Baker, 2009; Kimura, 2014; Poinsot et al., 2016; Kodera et al., 2017). It is categorized as essential AA that can be obtained from the diet and non-essential AA that is synthesized directly in the human body. Accordingly, cysteine is a non-essential AA as it can be directly synthesized in the body. However, the classification of essential AA should comprise the ability of the organism to synthesize carbon skeleton or just nitrogen compounds (Wu, 2009). Since cysteine carbon skeleton cannot be synthesized directly, thus it is under nutritionally essential AA (Wu, 2009).

Cysteine is a polar uncharged AA containing thiols SH side chain (Demirkol et al., 2004). It takes part in protein synthesis, cellular metabolism, stabilizer and also detoxification (Borase et al., 2015; Cebi et al., 2017) and important for stabilization of tertiary and quaternary protein conformation through disulfide bridges (Wirtz and Droux, 2005). In addition, protein associated and free thiols are responsible for the binding of metals and react with nucleophilic drugs and reactive oxygen (Plaza et al., 2018; Yin, 2015). The conversion of free thiol groups to disulfide bridges and vice versa constitutes a dynamic reactive system that is the basis for redox switches in protein (Wirtz and Droux 2005).

According to the food additives database from European List, cysteine is labelled under the E numbers of E910, E920 and E921 which are L-Cysteine, LCysteine Hydrochloride and L-Cysteine Hydrochloride Monohydrate, respectively. It falls under the antioxidant category that the proportions of the added cysteine amount shall not be greater than the maximum permitted proportions according to Food Regulations 1985 (Ministry of Health Malaysia, 1985). According to Food Drugs and Administration (FDA) the maximum volume of cysteine addition in dough is up to 0.009 parts per 100 parts as well as in flour bakery products.

Keratin hydrolysis is a huge production for cysteine additive. The keratin sources can become from four different sources which are pig bristles, human hair, duck feather and cow horn and it is considered as the major process production of cysteine in China (Ismail et al., 2014). The importance of cysteine in bakery ingredient required a cost-effective production to meet supply demand. Therefore, acid hydrolysis of keratin has been used by the manufacturers to produce cysteine (Ryu et al., 1997; Berehoiu et al., 2013; Xu et al., 2013). In order to obtain one kilogram of cysteine in keratin hydrolysis, at least $27 \mathrm{~kg}$ of $\mathrm{HCl}$ is needed and temperature must be set at $100^{\circ} \mathrm{C}$ for 6 hours (Berehoiu et al., 2013). Hence, human hair is chosen as one of the raw materials due to abundantly available for mass production. But there are also animal sources like feathers, bristles or hooves to be used as cysteine sources.

Based on the primary source of AA extraction it would rise some circumstances related to religion perspective especially on Muslim community.

"...Indeed, what He has forbidden to you is the flesh of dead animals and blood and the flesh of swine, and that which has been sacrificed to anyone other than Allah..." (2:172-173)

It is clearly being mentioned in the Quranic verse above that God prohibited anything related to swine for humankind to consume. This is included anything from head to toe and the essence of the swine itself including anything that related to the animal. The prohibition of swine is not solely purposed to obey God's rule but it is also related to some diseases in human (Nurdeng, 2009; Ali, 2014). This raised an ethical issue and consumer concern about its safety for consumption. It is offering some advantages which the human hair is cheap and it requires one ton of human hair to produce $100 \mathrm{~kg}$ of cysteine (Berehoiu et al., 2013). But, extraction of cysteine from human hair may produce an unpleasant odour, required a large volume of HCI, costly and not environmentally friendly (Ismail et al., 2014).

According to fatwa released by Department of Islamic Development Malaysia (JAKIM), any types of food that derived from the human body (hair) considered as haram (MS1500, 2009). Precisely, if cysteine's source is extracted from pig bristles and human hair it clearly violates halal principles which mentioned that whatever conducive to the haram is itself haram (Al-Qaradawi, 2007). This is because cysteine extracted from pig bristles and human hair may lead to epidemic generated from those sources. Consequently, it will relate to another halal principle which mentioned the prohibition of things due to their impurity and harmfulness (AlQaradawi, 2007). In order to protect and maintain the integrity of halal status, cysteine derived from animalbased is urged to be banned from entering Malaysia and mandatory posed for correct labelling ingredients of the source content (Idris, 2016). Meanwhile, according to the Turkish Food Codex Regulation on food additives, cysteine (E920) used as a food additive is banned in wheat flour (Cebi et al., 2017). 


\section{Analytical methods for cysteine determination}

The presence of cysteine and related thiols compound in bakery products, animal feeds, pharmaceutical and cosmetic products have increased demand for a reliable method in order to determine the authentication of cysteine's raw material. For the past few years, the implementation of halal guidelines by Malaysian government showed that the consumers demand quality and safe end products. Thus, Department of Islamic Development Malaysia (JAKIM) has been taking an initiative by implementing halal guideline in Malaysian standard (MS1500:2009 Halal Food Production, Preparation, Handling and Storage - General Guidelines) to ensure the quality and safety issue of end products. As been mentioned before, cysteine is used as food additives in bakery products and nutrient supplement in pharmaceutical and cosmetic products. Hence, the determination of cysteine should be taken into measured among the authorities for consumer safety and halal issue. To address this need, several methods have been developed and published for the determination of cysteine (Table 1).

\subsection{High performance liquid chromatography (HPLC)}

Recently, high performance liquid chromatography (HPLC) has been proven to be one of the commonly used instruments for the analysis of biological matrices and pharmaceutical preparations due to its high efficiency and good reproducibility. This method is able to determine concentrations of total cysteine content in wheat flour, bovine, porcine and fish gelatin (Azilawati et al., 2015; Lamp et al., 2018). Unfortunately, cysteine compound is often neglected in the amino acid analysis (AAA) through HPLC analytical measurement (Dai et al., 2014). This is because cysteine is susceptible to oxidation and reduction during hydrolysis mechanism (Barkholt and Jensen, 1989; Dai et al., 2014). Consequently, cysteine is prone to incomplete recovery in most of HPLC's AAA. This can be explained when thiols group that contains sulfur side chain may lead to the formation cysteine sulfinic/sulfenic/sulfonic acid due to reaction with residual oxygen during acid hydrolysis (Lamp et al., 2018). In a study done by Bartolomeo and

Table 1. Analytical methods for determination of cysteine

\begin{tabular}{cccc}
\hline Method & Approach & Description & References \\
\hline
\end{tabular}

$\begin{array}{llll}\text { Chromatographic } & \begin{array}{l}\text { High performance } \\ \text { liquid chromatography }\end{array} & \begin{array}{l}\text { Identification of cysteine amino acid through } \\ \text { amino acid analysis (AAA) }\end{array} & \begin{array}{l}\text { Dai } \text { et al. } \text { (2014) } \\ \text { Azilawati } \text { et al. (2015) }\end{array} \\ & & \text { Lamp et al. (2018) }\end{array}$

Determination of cysteine sulfhydryl bond (S-H) Li and Thomas (1991)

$\begin{array}{lll}\text { Raman spectroscopy } & \begin{array}{l}\text { stretching vibration is a unique probe of local } \\ \text { sulfhydryl (SH) structure and dynamics at }\end{array} & \text { Amir et al. (2013) } \\ & \text { wavelength 400-450nm. } & \text { Demir } \text { et al. (2015) }\end{array}$

wavelength $400-450 \mathrm{~nm}$. Fu et al. (2018)

Subramanian et al. (2009)

Demir et al. (2015)

Spectroscopic Attenuated Total Reflection-Fourier Characteristics cysteine amino acids based on the polar functional group. The side chain of

Hell et al. (2016)

Transform Infrared sulfhydryl $(\mathrm{SH})$ and amino groups $\left(\mathrm{NH}_{2}\right)$ can be (ATR-FTIR) represented in amide I and amide II band.

Chávez-Murillo et al. (2018)

Chen et al. (2018)

de la Rosa-Millán et al. (2018)

Flow injection spectrophotometric

Electrochemical biosensor

$\begin{array}{ll} & \text { Molecular imprinted } \\ & \text { polymer (MIP) and } \\ & \text { ultraviolet spectroscopy } \\ & \text { (UV-VIS) }\end{array}$

Collective

\section{Gold nanoparticle and UV-VIS}

Direct determination of cysteine through derivatization with 18-molybdophosphate (18AMP) and o-phtalaldehyde-N-acetyl-cysteine (OPA-NAC).

Electrochemical response is due to the reaction between designated carbon paste electrode and cysteine.

A combination of designated specific polymer and UV-Vis for cysteine compound identification.
Blasco et al. (1997)

Giljanović et al., (2011)

Petrova et al. (2016)

Santhiago and Vieira (2007)

Brinic et al. (2013)

Cai et al., (2014)

Hashemi et al. (2017)

Detection of cysteine compound is due to aggregation of cysteine compound around gold nanoparticles.
Shang et al. (2007)

Schulz and Baranska (2007)

Rastegarzadeh and Hashemi (2015)

Identification of cysteine side chain groups

ATR-FTIR and Raman spectroscopy

disulfide (S-S) and sulfhydryl $(\mathrm{S}-\mathrm{H})$ by utilizing both instruments capabilities.

Alternative $\quad$ Fluorescence probe Changes in phosphate buffer solution color Wang et al. (2018)


Maisano (2006), tryptophan and cysteine amino acids are destroyed during acid hydrolysis while serine and threonine suffered from partially lost in protein biopharmaceutical analysis.

Meanwhile, a mixture reagent of peptide synthesizer contained trityl-resin, fluorenylmethyloxycarbonyl chloride (fmoc) glycine, S-trityl-Fmoc-L-Cysteine and Fmoc-glu-tert-butyl ester were used to hydrolyze cysteine and other protein in wheat flour showed a great detection limit, $0.72 \mathrm{nmol} / \mathrm{g}$ in HPLC analysis (Reinbold et al., 2008). The detection is based upon the protein extraction from tens of different types of wheat flour. Based on cysteine detection in wheat flour, Reinbold et al. (2008) proved that a low concentration of glutathione and cysteine in flour from S-deficient wheat had a similar effect on the technological properties as the altered composition of gluten proteins.

\subsection{Molecular imprinted polymers (MIPs)}

Molecular imprinted polymers have been recognized due to their advantages involve in predetermined recognition ability, chemical stability, simple preparation and relative ease. Initially, this approach has received much attention in the fields of polymer science and chemical analysis. Theoretically, MIPs are synthetic polymers belong to specific cavities designed for a target molecule and are synthesized by the polymerization of different components (Lin et al., 2012). The stability of MIPs is based on adsorption capacity, active site accessibility and fixed shape (Hashemi et al., 2017). Hence, due to low-cost and easy preparation, MIP has gained wide acceptance as molecular recognition materials in developing sensor.

Hashemi et al. (2017) had used a combination of spectrophotometric detection (UV-Vis) based on MIP grafted with multiwall carbon nanotubes (MWCNTs) for separation and detection of cysteine in water samples. This method is based on the functionalization of MWCNTs by methacrylic acid (MAA) and subsequent polymerization for the preparation of a selective MIP/ MWCNTs composite for separation and enrichment of cysteine prior to its spectrophotometric determination. Tremendously, MIPs able to identified cysteine with a LOD as low as $2.3 \mathrm{ng} \mathrm{mL}^{-1}$. In fact, cysteine in human serum and water samples was successfully determined with recoveries ranging from $96.6 \%$ to $102.4 \%$.

Similarly, Cai et al. (2014), performed fluorescence determination of cysteine by using MIPs as an adsorbent with newly synthesis fluorescent detector chemodosimeter of rhodamine B derivative (RB1). The precipitation polymerization of cysteine MIP was prepared by mixing MAA, ethyleneglycol dimethacrylate
(EGDMA), acetonitrile and methanol. A novel chemodosimeter, RB1 has LOD up to $12.5 \mathrm{nM}$ to enhance the extraction of MIPs. This method successfully separated cysteine with other amino acids in aqueous solution.

\subsection{Raman spectroscopy}

Raman spectroscopy is a method to determine the chemical structures of molecules and interactions of molecules by representing the frequencies of molecular vibrations (Nemecek et al., 2013). The molecular vibrational will represent the peptide backbone and its side chains in protein analysis. The spectral positions, intensities, and polarization of the Raman bands are sensitive to protein secondary, tertiary, and quaternary structures and to side-chain orientations and local environments. The Raman band resulting from the cysteine sulfhydryl bond (S-H) stretching vibration is a unique marker of sulfhydryl (SH) structure (Nemecek et al., 2013).

The sulfhydryl will be used as Raman marker which occurs in a region of the spectrum between $2500 \mathrm{~cm}^{-1}$ to $2600 \mathrm{~cm}^{-1}$ (Nemecek et al., 2013). The interaction between sulfhydryl hydrogen bonding and the S-H stretching frequency yield a distinct wavenumber value for cysteinyl SH group identification. Meanwhile, a study done by Fu et al. (2018) recorded the wavenumber of SH group of crystal cysteine occurred at $2552 \mathrm{~cm}^{-1}$ and $2546 \mathrm{~cm}^{-1}$ (SH stretching) and $1070 \mathrm{~cm}^{-1}, 1000 \mathrm{~cm}^{-1}$ and $944 \mathrm{~cm}^{-1}$ (SH bonding). This difference of recorded wavenumber because of additional weak hydrogen bonds are by the SH group either with oxygen or sulfur atom (Minkov et al., 2009).

A study done by Baranski and Baranska (2008), showed that cysteine compound in the tobacco and carrot plant can be detected by using Raman spectroscopy. The spectroscopy of cysteine compound was further validated with hierarchical cluster analysis (HCA) in order to differentiate between genetically modified (GM) crops and non-genetically modified (Non-GM) crop. In addition, the wavenumber of $500-600 \mathrm{~cm}^{-1}$ was used in the experiment as a set of a cluster which based on the amide and S-S stretching band. Therefore, the presence of additional S-S bonds in the GM samples could explain the differences observed between the GM and non-GM spectra in a low wavenumber range. Thus, other than the sulfhydryl group used as a marker, peptide S-S group of cysteine can also provide helpful information for a reliable interpretation.

On the other hand, Cebi et al. (2017) used a combination of Raman microscopy with chemometric analysis of PCA and HCA, to differentiate ten types of 
wheat flour into the adulterated group and the nonadulterated group. The analytical technique was able to detect cysteine compound with LOD of $0.125 \%(\mathrm{w} / \mathrm{w})$. Raman spectral range was set between $500-2000 \mathrm{~cm}^{-1}$ prior to performing PCA and HCA analysis. The perfect combination of Raman spectroscopy and chemometric analysis was successfully discriminated and classified between non-adulterated and adulterated wheat flour.

\subsection{Attenuated Total Reflection-Fourier Transform Infrared (ATR-FTIR)}

Attenuated total reflection Fourier transform infrared (ATR-FTIR) spectroscopy is an internal reflection light incidence from a denser medium to lower index medium (air or sample) with an incident angle greater than critical angle $\theta \mathrm{c}$ (Vongsvivut et al., 2014). The condition cause the electromagnetic field (evanescent wave) decays exponentially in limited depth into the adjacent lower index sample. Any infrared (IR) absorbing material locating in contact to the interface interacts with the evanescent field causing a reduced IR intensity. The reduction of IR intensity is measured reflect to incident IR radiation and transformed into an ATR-FTIR spectrum (Vongsvivut et al., 2014). For example, polar functional groups (e.g. carbonyl compound) could easily be detected because of IR depends on the change of the permanent dipole moment of a chemical bond (Käppler et al., 2016).

Determination of cysteine compound residue by ATR-FTIR is widely introduced in wheat flour. This is because cysteine residue is one of the subfractions in wheat flour (Li et al., 2006). Many studies, found that valuable structural characteristics related to the interaction between protein components and amino acids sample that could be obtained from amide I and amide II band (Manley et al., 2002; Reinbold et al., 2008; Amir et al., 2013; Hell et al., 2016; Cebi et al., 2017; Chagas et al., 2018; Chen et al., 2018). The detection relied on the organization of the chemical structure in a sample. The protein organization structure can be identified in ATRFTIR through specific wavelength changes (de la RosaMillán et al., 2018). For example, the difference of amide $\mathrm{I}$ band which is assigned around $1600-1700 \mathrm{~cm}^{-1}$ can detect stretching vibration of $\mathrm{C}=\mathrm{O}$ and $\mathrm{C}-\mathrm{N}$ groups. Meanwhile, the amide II around is located around 510$1580 \mathrm{~cm}^{-1}$ in terms of in-plane N-H bending (40-60\%), C -N (18-40\%) and C-C (10\%) stretching (Amir et al., 2013). Thus, it could give us valuable information on the possible interactions that occurred at the molecular level that produce a significant impact on cysteine identification.

In a study done by $\mathrm{Li}$ et al. (2006), glutenin subfraction which consists of cysteine residue had been successfully differentiated between hydrated flour, gluten protein and flour. The result showed that hydrated flour had the highest peak in the amide I region at 1633 $\mathrm{cm}^{-1}$ and $1612 \mathrm{~cm}^{-1}$ (Li et al., 2006). This can be supported by data from Chávez-Murillo et al. (2018) where different proportions amide I band ratio at 1625 and $1616 \mathrm{~cm}^{-1}$ were recorded in different heat starch conditions. The study proved that heat treatment could rearrange the $\beta$-helix structure of protein in the flour. Moreover, ATR-FTIR analysis also proved that difference between a-helix and b-sheet secondary structures of the amide II group in different flour extracts (de la Rosa-Millán et al., 2018). Hence, it proved that, the capability of ATR-FTIR spectral measurement to determine the chemical composition of protein content qualitatively.

Apart from that, the major advantages of using ATRFTIR are a rapid, nondestructive, time-saving method that can detect a range of functional groups and is sensitive to changes in molecular structure. ATR-FTIR could provide information on the basis of chemical composition 20 and the physical state of the whole sample (Amir et al., 2013). Thus, makes it a valuable tool in compound identification.

\subsection{Flow injection spectrophotometric}

Most research used chromatographic analysis for cysteine detection in AAA. However, cysteine is hard to be measured because it can oxidize easily due to the presence of thiols compound (Blasco, 1997). Flow injection spectrophotometric is introduced for cysteine detection based on rapid proceeding redox reactions or on the derivatization of cysteine. Flow injection spectrophotometry is advantageous with high reproducibility and throughput up to 180 samples per hour by photometric detection (Petrova et al., 2016).

In order to improve rapidity of cysteine determination, Petrova et al. (2016) had used 18molybdophosphate (18-AMP) as a derivative reagent and a fabricated modified chip of polymethyl methacrylate (PMMA) by flow injection spectrophotometric in cysteine dietary supplement. Accordingly, the maximum spectrum observed reaction between 18-AMP and cysteine was $820 \mathrm{~nm}$. This method able to detect aqueous solution of cysteine (from $1 \times 10^{-5}$ to $1 \times 10^{-4} \mathrm{M}$ ) with a LOD of $0.03 \mathrm{mM}$ and 240 samples can be determined per hour. Meanwhile, Blasco et al. (1997) had used ophtalaldehyde-N-acetyl-cysteine (OPA-NAC) as a derivative reagent to detect cysteine in pharmaceutical capsule sample. Cysteine analytical range was $1.0 \times 10^{-5}$ to $1.0 \times 10^{-4} \mathrm{M}$. Yet, this method is proved to determine large many samples at a time with good reproducibility performance. Giljanović et al. (2001) had determined 
cysteine without sample pretreatment by using flow injection spectrophotometric method. The determination of cysteine is based on the reaction of $\mathrm{Pd}^{2+}$ ions with cysteine to form yellow $\mathrm{Pd}^{2+}$ cysteine complexes with the LOD $5.84 \mu \mathrm{mol} / 1$.

\subsection{Electrochemical biosensor}

Apart from fluorescence detection of cysteine by HPLC, electrochemical biosensor has also been applied to identify cysteine. This biosensor with an electrochemical transducer and is considered to be chemically modified electrode (CME) as electronic conducting, semiconducting or ionic conducting material. Additionally, electrochemical sensor is advantageous over other methods because of their low cost, fast response and low limit detection (LOD) (Zhou et al., 2007; Wang, et al., 2015). Theoretically, electrochemical response is due to the reaction between specific electrode designs with cysteine compound (Dharmapandian et al., 2010). Hence, lead to specific signal cysteine determination. Electrode accumulation is employed to provide concentration required for analysis by flameless atomic absorption spectrometry and anodic stripping voltammetry. In this sense, electrochemical methods present advantages of simplicity with easy miniaturization and high sensitivity (Brinić et al., 2003).

Brinic et al. (2013) developed bismuth film random array carbon fiber microelectrodes (BiF-RACFMEs), in conjugation with square wave cathodic stripping voltammetry (SWCSV) to determine cysteine in the dietary supplement. A carbon fiber electrode is applied due to their advantages over other carbon-based materials, such as decreasing of capacitive current, increasing of mass transfer rate, faster equilibrium time and negligibly ohmic drop. Cyclic voltammograms obtained at BiF-RACFMEs in acetate buffer ( $\mathrm{pH} 4.5)$ correspond to the deposition and dissolution of cysteine concentration. Hence, reduction current of bismuth cysteinate, formed on BiF-RACFMEs at $\mathrm{pH} 4.5$, is used as analytical signal for determination of cysteine and NAC. The detection limit is $0.028 \mu \mathrm{mol} / 1$, in the case of cysteine concentration between $1 \mu \mathrm{mol}^{-1} \mathrm{~L}$ and $10 \mu \mathrm{mol}^{-}$ ${ }^{1} \mathrm{~L}$ with sensitivity up to $398 \mathrm{nA} \mu \mathrm{mol}^{-1} \mathrm{~L}$.

In a study done by Santhiago and Vieira (2007) modified carbon paste electrode was successfully determined cysteine in pharmaceutical formulations. The electrode was modified with the introduction of laccase of the fungi Aspergillus oryzae. Fungi enzyme (laccase) was used in this study due to fast response to a specific substrate and highly selective. The determination of cysteine compound was based on the inhibition effect of cysteine compound with metal ions $\mathrm{Ag}^{+}, \mathrm{Zn}^{2+}, \mathrm{Hg}^{2+}$. The result showed that the recovery rate of cysteine is $87 \%$ and above and lifetime of the biosensor can be up to 9 months. Meanwhile, cysteine desulfhydrase enzyme (EC.4.4.1.1) was incorporated to determine cysteine compound in the pharmaceutical product (Hassan et al., 2007). The rate of cysteine by-products (sulfide ion) was potentiometric ally quantified as cysteine concentration. The result showed the concentration range of cysteine compound between $0.2-150 \mathrm{mgL}-1$ with a lower detection limit as low as $1 \mu \mathrm{molL}^{-1}$.

\subsection{Gold nanoparticles based colourimetric assay}

The interaction of gold nanoparticles (AuNPs) with cysteine and its derivatives is the basis of a number of bio nanotechnologies, and for these, the most important process is aggregation (or ant aggregation), which enables an array of colourimetric detection methods (Acres et al., 2014). The mechanism of aggregation will be observed when AuNPs were functionalized with cysteine and its dimer cystine, or the cysteine-derived tripeptide. The aggregation is can be seen when cysteine forms a two-layer boundary around the gold nanoparticles. The cysteine induced aggregation of AuNPs without further $\mathrm{pH}$ modification: the first by interparticle zwitterionic interaction and the second by interparticle hydrogen bonding (Abraham et al., 2010).

In order to improve the detection of cysteine using gold nanoparticles, Shang et al. (2007) had modified the method by prepared fluorescent conjugated polymerstabilized gold. The addition of cysteine, a thiolcontaining amino acid, the fluorescence of the colloidal solution increases significantly, indicating that cysteine can modulate the energy transfer between fluorophore and gold. This phenomenon then allows for sensitive detection of cysteine with a limit of detection (LOD) of $25 \mathrm{nM}$. The linear range of determination of cysteine is from $5 \times 10^{-8}$ to $4 \times 10^{-6} \mathrm{M}$. Another study showed that cysteine compound was successfully detected in tablet capsule with a limit of detection to $2.7 \mu \mathrm{mmolL}^{-1}$ through the combination of gold nanoparticles and UV-Vis spectrophotometer (Rastegarzadeh and Hashemi, 2015). Hence, a precise yet sensitive gold nanoparticle probe is a good analytical measure for cysteine compound detection.

\subsection{Application of chemometric analysis}

Chemometric is a combination of statistical and mathematical methods into chemistry. In particular, chemometric is unsupervised multivariate methods allow for more advanced treatment of data derived from chemical mixtures into simplest forms. It provides a large number of tools for pattern recognition, classification and identification which could increase the speed and meet the analysis objective (Christensen and 
Tomasi, 2007). For example, transmittance values from ATR-FTIR and Raman spectroscopy could be used as a variable to determine intercorrelations between measured variables (Oliveri and Simonetti, 2016). The exploration of measured variables from various analysis tools discussed above is advantageous in order to transform data based on origin sources. There are several tools applied in the chemometric analysis which are principal component analysis (PCA), hierarchical analysis (HCA), partial least squares regression (PLS) and orthogonal projections to latent structures discriminant analysis (OPLS-DA). Combination of PCA, HCA and Raman spectroscopy were successfully differentiating GM crop and non-GM crop of carrot and tobacco plants (Baranski and Baranksa, 2008). The wavenumber range between $500-600 \mathrm{~cm}^{-1}$ was selected throughout this study as a variable marker. This can be supported by a study done by Cebi et al. (2017) where a combination of HCA, PCA and Raman microscopy differentiate ten types of wheat flour into the adulterated group and the non-adulterated group. On the other hand, ATR-FTIR were able to discriminate a total of 144 honey floral sources according to their geographical origin with the aid of HCA and PCA (Gok et al., 2015). The samples were grouping based on spectral range $1800-750 \mathrm{~cm}^{-1}$ in HCA. In addition, ATR-FTIR spectroscopy successfully differentiated bread wheat species with the combination of PCA and HCA (Demir et al., 2015). The whole ATRFTIR spectra were used in order to cluster the samples into a separated group.

\section{Conclusion}

Cysteine has a good prospect in the food industry to be recognized worldwide. As a part of the protein, cysteine is an essential nutrient additive that may benefit for the consumers. However, the production of cysteine remained scarce for consumer trust. There is a need for method development in the determination of cysteine. Spectroscopic methods such as Raman and ATR-FTIR is a versatile analysis technique for determining the chemical composition of cysteine compound. This is due to the ability of light ray to absorb thiol linkage of cysteine compound. The analysis is robust and required minimal sample preparation. In addition, the combination of chemometric analysis such as PCA or HCA could increase the efficiency and reliability of the result.

\section{Acknowledgement}

This work was supported by the IIUM Research Initiative Grant Scheme [RIGS16-068-0232] from the International Islamic University Malaysia (IIUM), Selangor, Malaysia.

\section{References}

Abraham, A., Mihaliuk, E., Kumar, B., Legleiter, J. and Gullion, T. (2010). Solid-State NMR Study of Cysteine on Gold Nanoparticles. The Journal of Physical Chemistry C, 114, 18109-18114. https:// doi.org/10.1021/jp107112b

Acres, R.G., Feyer, V., Tsud, N., Carlino, E. and Prince, K.C. (2014). Mechanisms of aggregation of cysteine functionalized gold nanoparticles. Journal of Physical Chemistry C, 118, 10481-10487. https:// doi.org/10.1021/jp502401w

Ali, M. (2014). Perspectives on Drug Addiction in Islamic History and Theology. Religions, 5(3), 912928. https://doi.org/10.3390/rel5030912

Al-Qaradawi, Y. (1994). The lawful and the prohibited in Islam (El-Helbawy, K. and Siddiqui, M.M., Trans.) USA: American Trust Publishers.

Amir, R.M., Anjum, F.M., Khan, M.I., Khan, M.R., Pasha, I. and Nadeem, M. (2013). Application of Fourier transform infrared (FTIR) spectroscopy for the identification of wheat varieties. Journal of Food Science and Technology, 50(5), 1018-1023. https:// doi.org/10.1007/s13197-011-0424-y

Azilawati, M.I., Hashim, D.M., Jamilah, B. and Amin, I. (2015). RP-HPLC method using 6-aminoquinolyl-Nhydroxysuccinimidyl carbamate incorporated with normalization technique in principal component analysis to differentiate the bovine, porcine and fish gelatins. Food Chemistry, 172, 368-376. https:// doi.org/10.1016/j.foodchem.2014.09.093

Baker, D.H. (2009). Advances in protein-amino acid nutrition of poultry. Amino Acids, 37(1), 29-41. https://doi.org/10.1007/s00726-008-0198-3

Baranski, R. and Baranska, M. (2008). Discrimination between nongenetically modified (Non-GM) and GM plant tissue expressing cysteine-rich polypeptide using FT-Raman spectroscopy. Journal of Agricultural and Food Chemistry, 56(12), 44914496. https://doi.org/10.1021/jf800410m

Barkholt, V. and Jensen, A.L. (1989). Amino acid analysis: Determination of cysteine plus halfcysteine in proteins after hydrochloric acid hydrolysis with a disulfide compound as additive. Analytical Biochemistry, 177(2), 318-322. https:// doi.org/10.1016/0003-2697(89)90059-6

Bartolomeo, M.P. and Maisano, F. (2006). Validation of a reversed-phase HPLC method for quantitative amino acid analysis. Journal of Biomolecular Techniques, 17(2), 131-137.

Blasco, F. (1997). Use of $\mathrm{pH}$ gradients in continuousflow systems and multivariate regression techniques applied to the determination of methionine and 
cysteine in pharmaceuticals. Analytica Chimica Acta, 348(1-3), 151-159. https://doi.org/10.1016/S00032670(97)00063-9

Brinić, S., Vladislavić, N., Buzuk, M., Bralić, M. and Šolić, M. (2013). Bismuth film random array carbon fiber microelectrodes for determination of cysteine and N-acetyl cysteine. Journal of Electroanalytical Chemistry, 705, 86-90. https://doi.org/10.1016/ j.jelechem.2013.07.031

Cai, X., Li, J., Zhang, Z., Wang, G., Song, X., You, J. and Chen, L. (2014). Chemodosimeter-based fluorescent detection of L-cysteine after extracted by molecularly imprinted polymers. Talanta, 120, 297 303. https://doi.org/10.1016/j.talanta.2013.12.019

Cao, C., Xie, J., Hou, L., Zhao, J., Chen, F., Xiao, Q. and Fan, M. (2017). Effect of glycine on reaction of cysteine-xylose: Insights on initial Maillard stage intermediates to develop meat flavour. Food Research International, 99(Part 1), 444-453. https:// doi.org/10.1016/j.foodres.2017.06.012

Cebi, N., Dogan, C.E., Develioglu, A., Yayla, M.E.A. and Sagdic, O. (2017). Detection of L-Cysteine in wheat flour by Raman microspectroscopy combined chemometrics of HCA and PCA. Food Chemistry, 228, 116-124. https://doi.org/10.1016/ j.foodchem.2017.01.132

Chagas, J.C.C., Ferreira, M.A., Faciola, A.P., Machado, F.S., Campos, M.M., Entjes, M.R. and Marcondes, M.I. (2018). Effects of methionine plus cysteine inclusion on performance and body composition of liquid-fed crossbred calves fed a commercial milk replacer and no starter feed. Journal of Dairy Science, 101(7), 1-11. https://doi.org/10.3168/ jds.2017-13615

Chávez-Murillo, C.E., Veyna-Torres, J.I., CavazosTamez, L.M., de la Rosa-Millán, J. and SernaSaldívar, S.O. (2018). Physicochemical characteristics, ATR-FTIR molecular interactions and in vitro starch and protein digestion of thermally -treated whole pulse flours. Food Research International, 105, 371-383. https://doi.org/10.1016/ j.foodres.2017.11.029

Chen, G., Ehmke, L., Sharma, C., Miller, R., Faa, P., Smith, G. and Li, Y. (2018). Physicochemical properties and gluten structures of hard wheat flour doughs as affected by salt. Food Chemistry, 275, 569 -576 .

j.foodchem.2018.07.157

Christensen, J.H. and Tomasi, G. (2007). Practical aspects of chemometrics for oil spill fingerprinting. Journal of Chromatography A, 1169(1-2), 1-22. https://doi.org/10.1016/j.chroma.2007.08.077
Dai, Z., Wu, Z., Jia, S. and Wu, G. (2014). Analysis of amino acid composition in proteins of animal tissues and foods as pre-column o-phthaldialdehyde derivatives by HPLC with fluorescence detection. Journal of Chromatography B: Analytical Technologies in the Biomedical and Life Sciences, 964, 116-127. https://doi.org/10.1016/ j.jchromb.2014.03.025

de la Rosa-Millán, J., Orona-Padilla, J.L., FloresMoreno, V.M. and Serna-Saldívar, S.O. (2018). Physicochemical, functional andATR-FTIR molecular analysis of protein extracts derived from starchy pulses. International Journal of Food Science and Technology, 53(6), 1414-1424. https:// doi.org/10.1111/ijfs.13719

Demir, P., Onde, S. and Severcan, F. (2015). Phylogeny of cultivated and wild wheat species using ATRFTIR spectroscopy. Spectrochimica Acta - Part A: Molecular and Biomolecular Spectroscopy, 135, 757 -763. https://doi.org/10.1016/j.saa.2014.07.025

Demirkol, O., Adams, C. and Ercal, N. (2004). Biologically important thiols in various vegetables and fruits. Journal of Agricultural and Food Chemistry, 52(26), 8151-8154. https:// doi.org/10.1021/jf040266f

Dharmapandian, P., Rajesh, S., Rajasingh, S., Rajendran, A. and Karunakaran, C. (2010). Electrochemical cysteine biosensor based on the selective oxidaseperoxidase activities of copper, zinc superoxide dismutase. Sensors and Actuators, B: Chemical, 148 (1), 17-22. https://doi.org/10.1016/j.snb.2010.04.023

Frape, D.L., Wilkinson, J., Chubb, L.G., Buchanan, A.M. and Coppock, J.B.M. (1971). Use of Lcysteine in bread baking-results of a multigeneration feeding experiment with breeding rats. Journal of the Science of Food and Agriculture, 22 (2), 65-68. https://doi.org/10.1002/jsfa.2740220205

Fu, C., Dai, C., Du, B., Li, P., Lei, L., Hu, F. and Jiang, Z. (2018). Raman spectroscopic study of orthorhombic L-cysteine under pressure up to 20.2 GPa. Journal of Molecular Structure, 1171, 196 -201. https://doi.org/10.1016/j.molstruc.2018.05.061

Giljanović, J., Brkljaèa, M. and Prkić, A. (2011). Flow injection spectrophotometric determination of Nacetyl-L-cysteine as a complex with palladium (II). Molecules, 16(9), 7224-7236. https:// doi.org/10.3390/molecules16097224

Gmunder, H., Eck, H.-P., Benninghoff, B., Roth, S. and Droge, W. (1990). Macrophages Regulate Intracellular Glutathione Levels of Lymphocytes. Evidence for an 1mmunoregulatory Role of Cysteine'. Cellular Immunology, 129(1), 32-46. https://doi.org/10.1016/0008-8749(90)90184-S 
Hashemi, M., Nazari, Z. and Bigdelifam, D. (2017). A molecularly imprinted polymer based on multiwalled carbon nanotubes for separation and spectrophotometric determination of L-cysteine. Microchimica Acta, 184(8), 2523-2532. https:// doi.org/10.1007/s00604-017-2236-x

Hassan, S.S.M., El-Baz, A.F. and Abd-Rabboh, H.S.M. (2007). A novel potentiometric biosensor for selective 1-cysteine determination using 1-cysteinedesulfhydrase producing Trichosporon jirovecii yeast cells coupled with sulfide electrode. Analytica Chimica Acta, 602(1), 108-113. https:// doi.org/10.1016/j.aca.2007.09.007

Hell, J., Prückler, M., Danner, L., Henniges, U., Apprich, S., Rosenau, T. and Böhmdorfer, S. (2016). A comparison between near-infrared (NIR) and midinfrared (ATR-FTIR) spectroscopy for the multivariate determination of compositional properties in wheat bran samples. Food Control, 60, 365-369.

https://doi.org/10.1016/

j.foodcont.2015.08.003

Hunt, S. (1985). Degradation of Amino Acids Accompanying in vitro Protein Hydrolysis, Chap. 12. In Barrett, C.G. (Ed.) Chemistry and Biochemistry of the Amino Acids, p. 376-397. Dordrecht, Switzerland: Springer. https:// doi.org/10.1007/978-94-009-4832-7_12

Idris, S.M. (2016). CAP: Ban animal-based L-cysteine. Malaysia Kini. Retrieved from Malaysia Kini website: https://www.malaysiakini.com/ letters/349328.

Ismail, N.I., Hashim, Y.Z.H.-Y., Jamal, P., Othman, R. and Salleh, H.M. (2014). Production of Cysteine: Approaches, Challenges and Potential Solution. International Journal of Biotechnology for Wellness Industries, 3(3), 95-101. https:// doi.org/10.6000/1927-3037.2014.03.03.3

Käppler, A., Fischer, D., Oberbeckmann, S., Schernewski, G., Labrenz, M., Eichhorn, K. and Voit, B. (2016). Analysis of environmental microplastics by vibrational microspectroscopy: FTIR, Raman or both? Analytical and Bioanalytical Chemistry, 408, 8377-8391. https://doi.org/10.1007/ s00216-016-9956-3

Kimura, H. (2014). The physiological role of hydrogen sulfide and beyond. Nitric Oxide - Biology and Chemistry, 41, 4-10. https://doi.org/10.1016/ j.niox.2014.01.002

Kodera, Y., Ushijima, M., Amano, H., Suzuki, J.I. and Matsutomo, T. (2017). Chemical and biological properties of s-1-propenyl-1-cysteine in aged garlic extract. Molecules, 22(4), 1-19. https:// doi.org/10.3390/molecules22040570
Lamp, A., Kaltschmitt, M. and Lüdtke, O. (2018). Improved HPLC-method for estimation and correction of amino acid losses during hydrolysis of unknown samples. Analytical Biochemistry, 543, 140 -145. https://doi.org/10.1016/j.ab.2017.12.009

Li, H. and Thomas, G.J.Jr. (1991). Cysteine conformation and sulfhydryl interactions in proteins and viruses. I. Correlation of the Raman S-H band with hydrogen bonding and intramolecular geometry in model compounds. Journal of American Chemists Society, 113, 456-462.

Li, W., Dobraszczyk, B.J., Dias, A. and Gil, A.M. (2006). Polymer conformation structure of wheat proteins and gluten subfractions revealed by ATRFTIR. Cereal Chemistry, 83(4), 407-410. https:// doi.org/10.1094/CC-83-0407

Lin, Z., Cheng, W., Li, Y., Liu, Z., Chen, X. and Huang, C. (2012). A novel superparamagnetic surface molecularly imprinted nanoparticle adopting dummy template: An efficient solid-phase extraction adsorbent for bisphenol A. Analytica Chimica Acta, 720, 71-76. $\quad$ https://doi.org/10.1016/ j.aca.2012.01.020

Manley, M., Van Zyl, L. and Osborne, B.G. (2002). Using fourier transform near infrared spectroscopy in determining kernel hardness, protein and moisture content of whole wheat flour. Journal of Near Infrared Spectroscopy, 10(1), 71-76. https:// doi.org/10.1255/jnirs.323

Ministry of Health Malaysia. (1985). Food Regulations 1985. Part V Food Additive And Nutrient Supplement. Retrieved on May 31, 2020, from http:// fsis2 .moh.gov .my/fosimv2 /HOM/frm HOMFARSec. aspx $? \mathrm{id}=21$.

Minkov, V.S., Tumanov, N.A., Kolesov, B.A., Boldyreva, E.V. and Bizyaev, S.N. (2009). Phase transitions in the crystals of 1- and dl-cysteine on cooling: the role of the hydrogen-bond distortions and the side-chain motions. 2. DL-cysteine. Journal of Physical Chemistry B, 113(15), 5262-5272. https://doi.org/10.1021/jp810355a

MS1500:2009 Halal Food - Production, Preparation, Handling and Storage - General Guidelines

Nemecek, D., Stepanek, J. and Thomas Jr., G.J. (2013). Raman spectroscopy of proteins and nucleoproteins. Current Protocols in Protein Science, 71(1), 17.8.117.8.52.

https:// doi.org/10.1002/0471140864.ps1708s71

Nurdeng, D. (2009). Lawful and unlawful foods in Islamic law focus on Islamic medical and ethical aspects. International Food Research Journal, 16(4), 469-478. 
Oliveri, P. and Simonetti, R. (2016). Chemometrics for Food Authenticity Applications. In Downey, G. (Ed.). Advances in Food Authenticity Testing, p. 701 -728USA: Woodhead Publishing.

Petrova, A.V., Ishimatsu, R., Nakano, K., Imato, T., Vishnikin, A.B., Moskvin, L.N. and Bulatov, A.V. (2016). Flow-Injection Spectrophotometric Determination of Cysteine in Biologically Active Dietary Supplements. Journal of Analytical Chemistry, 71, 172-178. https://doi.org/10.1134/ S1061934816020118

Plaza, N.C., García-Galbis, M.R. and Martínez-Espinosa, R.M. (2018). Effects of the usage of L-Cysteine (LCys) on human health. Molecules, 23(3), 1-13. https://doi.org/10.3390/molecules23030575

Poinsot, V., Ong-Meang, V., Gavard, P. and Couderc, F. (2016). Recent advances in amino acid analysis by capillary electromigration methods, 2013-2015. Electrophoresis, 37(1), 142-161. https:// doi.org/10.1002/elps.201500302

Rastegarzadeh, S. and Hashemi, F. (2015). Gold nanoparticles as a colorimetric probe for the determination of $\mathrm{N}$-acetyl-1-cysteine in biological samples and pharmaceutical formulations. Analytical Methods, 7(4), 1478-1483. https://doi.org/10.1039/ c4ay01961j

Reinbold, J., Rychlik, M., Asam, S., Wieser, H. and Koehler, P. (2008). Concentrations of total glutathione and cysteine in wheat flour as affected by sulfur deficiency and correlation to quality parameters. Journal of Agricultural and Food Chemistry, 56(16), 6844-6850. https:// doi.org/10.1021/jf800880n

Ryu, O.H., Ju, J.Y. and Shin, C.S. (1997). Continuous Lcysteine production using immobilized cell reactors and product extractors. Process Biochemistry, 32(3), 201-209. https://doi.org/10.1016/S0032-9592(96) 00061-1

Santhiago, M. and Vieira, I.C. (2007). 1-Cysteine determination in pharmaceutical formulations using a biosensor based on laccase from Aspergillus oryzae. Sensors and Actuators, B: Chemical, 128(1), 279-285. https://doi.org/10.1016/j.snb.2007.06.012

Schulz, H. and Baranska, M. (2007). Identification and quantification of valuable plant substances by IR and Raman spectroscopy. Vibrational Spectroscopy, 43 (1), 13-25. https://doi.org/10.1016/ j.vibspec.2006.06.001

Shang, L., Qin, C., Wang, T., Wang, M., Wang, L. and Dong, S. (2007). Fluorescent conjugated polymerstabilized gold nanoparticles for sensitive and selective detection of cysteine. Journal of Physical
Chemistry C, 111(36), 13414-13417. https:// doi.org/10.1021/jp073913p

Sirko, A., Błaszczyk, A. and Liszewska, F. (2004). Overproduction of SAT and/or OASTL in transgenic plants: A survey of effects. Journal of Experimental Botany, 55(404), 1881-1888. https:// doi.org/10.1093/jxb/erh151

Subramanian, A., Harper, W.J. and Rodriguez-Saona, L.E. (2009). Rapid prediction of composition and flavour quality of cheddar cheese using ATR-FTIR spectroscopy. Journal of Food Science, 74(3). https://doi.org/10.1111/j.1750-3841.2009.01111.x

Tamura, Y., Nishino, M., Ohmachi, T. and Asada, Y. (1998) N-Carbamoyl-L-Cysteine as an Intermediate in the Bioconversion from $\mathrm{D}$, L-2-Amino- $\Delta$ 2Thiazoline-4-Carboxylic Acid to L-Cysteine by Pseudomonas sp. ON-4a, Bioscience, Biotechnology, and Biochemistry, 62(11), 22262229, DOI: $10.1271 / \mathrm{bbb} .62 .2226$

Vongsvivut, J., Heraud, P., Zhang, W., Kralovec, J.A., McNaughton, D. and Barrow, C.J. (2014). Rapid Determination of Protein Contents in Microencapsulated Fish Oil Supplements by ATRFTIR Spectroscopy and Partial Least Square Regression (PLSR) Analysis. Food and Bioprocess Technology, 7(1), 265-277. https://doi.org/10.1007/ s11947-013-1122-8

Wada, M. and Takagi, H. (2006). Metabolic pathways and biotechnological production of L-cysteine. Applied Microbiology and Biotechnology, 73(1), 4854. https://doi.org/10.1007/s00253-006-0587-z

Wang, J., Wang, H., Hao, Y., Yang, S., Tian, H., Sun, B. and Liu, Y. (2018). A novel reaction-based fluorescent probe for the detection of cysteine in milk and water samples. Food Chemistry, 262, 6771. https://doi.org/10.1016/j.foodchem.2018.04.084

Wang, X., Luo, C., Li, L. and Duan, H. (2015). Highly selective and sensitive electrochemical sensor for 1cysteine detection based on graphene oxide/ multiwalled carbon nanotube/manganese dioxide/ gold nanoparticles composite. Journal of Electroanalytical Chemistry, 757, 100-106. https:// doi.org/10.1016/j.jelechem.2015.09.023

Wirtz, M. and Droux, M. (2005). Synthesis of the sulfur amino acids: Cysteine and methionine. Photosynthesis Research, 86(3), 345-362. https:// doi.org/10.1007/s11120-005-8810-9

Wirtz, M., Droux, M. and Hell, R. (2004). O-acetylserine (thiol) lyase: An enigmatic enzyme of plant cysteine biosynthesis revisited in Arabidopsis thaliana. Journal of Experimental Botany, 55(404), 17851798. https://doi.org/10.1093/jxb/erh201 
Wu, G. (2009). Amino acids: Metabolism, functions, and nutrition. Amino Acids, 37(1), 1-17. https:// doi.org/10.1007/s00726-009-0269-0

$\mathrm{Wu}, \mathrm{G}$. (2013). Functional amino acids in nutrition and health. Amino Acids, 45(3), 407-411. https:// doi.org/10.1007/s00726-013-1500-6

Xu, L., Wang, Z., Mao, P., Liu, J., Zhang, H., Liu, Q. and Jiao, Q.C. (2013). Enzymatic synthesis of Sphenyl-1-cysteine from keratin hydrolysis industries wastewater with tryptophan synthase. Bioresource Technology, 133, 635-637. https://doi.org/10.1016/ j.biortech.2013.02.011

Yin, Y. (2015). L-Cysteine metabolism and its nutritional implications. Molecular Nutrition and Food Research, 60(1), 134-146. https:// doi.org/10.1002/mnfr.201500031

Zhou, M., Ding, J., Guo, L. P. and Shang, Q. K. (2007). Electrochemical behavior of L-cysteine and its detection at ordered mesoporous carbon-modified glassy carbon electrode. Analytical Chemistry, 79 (14), 5328-5335. https://doi.org/10.1021/ac0703707 